Blindness

\title{
What is the cost of blindness?
}

\section{Meads, C Hyde}

\section{Ideally an independent cost study based on the experiences of a cohort of elderly people with failing eyesight should be undertaken}

\begin{abstract}
A ge related macular degeneration (AMD), particularly the wet variant, is an important cause of blindness and a serious public health challenge in older people. A recent health technology appraisal for the National Institute for Clinical Excellence (NICE) of a new treatment, photodynamic therapy for AMD, included the requirement to model the cost utility of treatment. (Cost utility analysis is a form of economic evaluation which compares the cost of two alternative interventions and their health outcomes expressed as a single index that combines length of life and quality of life. Cost utility is usually given as a cost per quality adjusted life year.)
\end{abstract}

In this it was necessary to include the costs averted by the treatment preventing people becoming blind. ${ }^{1}$ These are costs averted that the government would have spent supporting the blind person, such as visual rehabilitation, social services, or local authority care rather than the cost of blindness to the individual affected. ${ }^{2}$ Generating a cost of blindness is a generic feature of cost utility models of a variety of other treatments in similar eye conditions such as diabetic retinopathy. ${ }^{3}$ In these, the blindness cost estimate is often based on a 1990 US federal budgetary cost. $^{5}$ This estimate for a blind person over retirement age was very low (US\$32). Obviously it did not take into account other public expenditure so would have been inappropriate to a UK based health technology assessment more than 10 years later. Another approach taken when conducting cost utility analyses is to only include the cost of treatment and ignore the costs averted. This can be done if a "for profit" third party insurer perspective is taken, but again not if a publicly funded health service or societal perspective is taken. ${ }^{6}$

The support that different countries' public health, social provision, or health insurers give to people who become blind is also important. In general, the more support that is given the higher the cost. Since provision is different, the cost of blindness calculated in one country may not be applicable to another. Also, the low vision threshold at which benefits accrue may vary. Legal blindness is defined differently by different countries or organisations but a fairly standard definition is visual acuity of 6/60 (or 20/200) or worse in the better eye or a visual field less than or equal to 20 degrees in the better eye. In England and Wales a certificate is issued called a BD8. On this, the legal definition of blindness is "so blind as to be unable to perform any work for which eyesight is essential." The visual acuity recommendations are 3/60 or worse in the better eye (corrected visual acuity) or $6 / 60$ or worse in the better eye with markedly restricted fields. The issuing of a BD8 certificate starts a process of assessing needs and providing appropriate services

Obviously, the BD8 definition was set up with reference to working age people becoming blind or partially sighted. People become blind at any age, so their needs and therefore the costs will be different depending on whether the person is a child, of working age, or above retirement age. The cost of blindness may also vary depending on the medical condition experienced. For example, uveitis can cause both temporary and permanent blindness; during an episode of temporary blindness patients will not be eligible for registration and so not receive the same services. Cataract is usually amenable to surgery so few people are registered blind where this condition is the main cause of visual loss.?

During the NICE health technology appraisal, there was a need to establish, as accurately as possible, the average cost of blindness in the United Kingdom in older people with AMD. A survey of estimates of the cost of blindness, particularly in AMD or diabetic retinopathy was carried out. Available annual cost estimates are shown in Table 1. All costs are inflated to December 2002 using the retail price index.

All are top down cost studies and all except the study of Chiang et al ${ }^{5}$ take a public expenditure perspective. The most detailed study is that of Wright et $a l^{8}$ but this does not give the highest adjusted cost. It is the only cost study not linked to cost effectiveness. Three (ScHARR 2001, ${ }^{9}$ Greiner 2001, ${ }^{10}$ and Smith $^{11}$ ) are associated with cost utility analyses carried out for Novartis Pharmaceuticals AG, Switzerland, before the NICE appraisal of photodynamic therapy. The other UK estimate ${ }^{12}$ and one US estimate ${ }^{13}$ were for cost effectiveness of screening programmes.

When reviewing the literature it became clear that there was a wide range of available cost estimates. We needed to see whether the higher or lower estimates were the most valid. There was a need for an accurate measure of UK costs of blindness in $\mathrm{AMD}$ in order to establish cost utility of photodynamic therapy. As there was insufficient time to conduct a bottom up cost study (that is, a cohort study of a group of people with AMD to record the costs they incurred over a period of time), a detailed top down study of the main cost factors and the proportions of people with AMD affected was undertaken in order to estimate the total cost of the condition.

\section{METHODS}

The potential costs of blindness to the NHS and to other local and central government funded agencies in the first and subsequent years were estimated from a variety of published and unpublished sources. Elderly people with low vision have a range of likelihoods of incurring each of these costs and these probabilities were also estimated from published sources.

Costs and probabilities were collected in the following categories:

- Low vision clinic assessment, provision of low vision aids, training in their use

- Low vision rehabilitation in activities for daily living

- Acute admission to geriatric ward for broken hip, total hip replacement, rehabilitation

- Registration as blind or partially sighted

- Admission into residential care

- Community care-provision of a home care worker

- Social security benefits, in particular attendance allowance

- Blind person's tax allowance

- Treatment and support of an elderly person with depression.

The NHS alone funds some services, whereas for others such as blindness registration, there is joint funding by NHS and local government. More recent 
Table 1 Published estimates of cost of blindness in AMD and diabetic retinopathy

\begin{tabular}{|c|c|c|c|c|c|}
\hline Study (ref) & $\begin{array}{l}\text { Place and date of } \\
\text { cost estimate }\end{array}$ & $\begin{array}{l}\text { Category and } \\
\text { condition }\end{array}$ & Original estimate & $\begin{array}{l}\text { Inflated to } \\
\text { December } 2002\end{array}$ & Factors included in estimate \\
\hline $\begin{array}{l}\text { Foulds et } \\
\text { al,1983 (12) }\end{array}$ & Scotland 1981 & Adult & $£ 3575$ & $£ 7433^{*}$ & $\begin{array}{l}\text { Staffing costs of blind welfare service, state } \\
\text { benefits }\end{array}$ \\
\hline \multirow{4}{*}{$\begin{array}{l}\text { ScHARR, } \\
2001 \text { (9) }\end{array}$} & \multirow[t]{4}{*}{ UK 2000‡ } & Older person with & $£ 153$ & $£ 159^{*}$ & Registration, social services at home \\
\hline & & $A M D$, transition cost & $£ 0-£ 194$ & $£ 0-£ 201^{*}$ & assessment, low vision aids \\
\hline & & \multirow[t]{2}{*}{ Annual ongoing costs } & $£ 343$ & $£ 356^{*}$ & \multirow[t]{2}{*}{ Attendance allowance, residential care } \\
\hline & & & $£ 33-£ 1593$ & $£ 34-£ 1651^{*} \dagger$ & \\
\hline $\begin{array}{l}\text { Smith et al, } \\
2001 \text { (11) }\end{array}$ & UK 2000‡ & $\begin{array}{l}\text { Older person with } \\
\text { AMD }\end{array}$ & $£ 722-£ 2519$ & $£ 748-£ 2611^{*} \dagger$ & $\begin{array}{l}\text { Visual aids, optician visit, sensory disabilities } \\
\text { team visit, social security payment, residential } \\
\text { care }\end{array}$ \\
\hline \multirow{4}{*}{$\begin{array}{l}\text { Chiang et al, } \\
1992 \text { (5) }\end{array}$} & \multirow[t]{4}{*}{ USA 1990} & Child $3-5$ years & US\$2187 & $£ 1688^{*} \dagger$ & \multirow{5}{*}{$\begin{array}{l}\text { Income assistance programmes, health } \\
\text { insurance programs (Medicare, Medicaid), tax } \\
\text { losses from reduced potential earnings, food } \\
\text { stamps, special education programmes } \\
\text { Home visits by either a public health nurse, } \\
\text { occupational therapist and/or vocational/ } \\
\text { rehabilitation counsellor }\end{array}$} \\
\hline & & Child 6-21 years & US\$1778 & $£ 1373^{*} \dagger$ & \\
\hline & & Adult $21-64$ years & US\$11896 & $£ 9184^{*} \dagger$ & \\
\hline & & Retired $65+$ & US\$32 & $£ 24^{*} \dagger$ & \\
\hline $\begin{array}{l}\text { Dasbach et al, } \\
1991 \text { (13) }\end{array}$ & USA $1985 \ddagger$ & $\begin{array}{l}\text { Adult with diabetic } \\
\text { retinopathy }\end{array}$ & US\$5100 & $£ 5391^{*} \dagger$ & \\
\hline \multirow[t]{3}{*}{$\begin{array}{l}\text { Wright et al, } \\
2000 \text { (8) }\end{array}$} & \multirow[t]{3}{*}{ Australia 1999} & Child $<16$ years & $\begin{array}{l}\text { Aus } \$ 15948 \\
(\$ 5106-\$ 23798)\end{array}$ & $\begin{array}{l}£ 6714^{*} \dagger \\
\quad(£ 2150-£ 9987)\end{array}$ & \multirow{3}{*}{$\begin{array}{l}\text { Subsidies and concessions linked to the Age } \\
\text { Pension (Blind), Disability Support Pension } \\
\text { (Blind) or Carer Allowance, pharmaceutical } \\
\text { benefits, rent assistance, employment entry } \\
\text { assistance, free postage, transport concessions, } \\
\text { tax subsidies, household concessions such as } \\
\text { reduced electricity and gas payments, } \\
\text { occupational therapy, low vision clinics and } \\
\text { devices, day centre use, visiting teacher } \\
\text { services }\end{array}$} \\
\hline & & $\begin{array}{l}\text { Adult }>21 \text { years with } \\
\text { diabetic retinopathy }\end{array}$ & $\begin{array}{l}\text { Aus } \$ 17701 \\
(\$ 9669-\$ 26720)\end{array}$ & $\begin{array}{l}£ 7452^{*} \dagger \\
\quad(£ 4070-£ 11250)\end{array}$ & \\
\hline & & $\begin{array}{l}\text { Retired }(M>65 \\
F>62) \text { with } A M D\end{array}$ & $\begin{array}{l}\text { Aus } \$ 14686 \\
(\$ 9749-\$ 22507)\end{array}$ & $\begin{array}{l}£ 6183^{*} \dagger \\
\quad(£ 4104-£ 9476)\end{array}$ & \\
\hline \multirow{3}{*}{$\begin{array}{l}\text { Greiner, } \\
2001 \text { (10) }\end{array}$} & \multirow[t]{3}{*}{ Switzerland, 1998} & Older person with & CHF2303 (good vision) & $£ 1042 * \dagger$ & \multirow{3}{*}{$\begin{array}{l}\text { Optical and non-optical aids, services provided } \\
\text { by district nurses and health visitors, low vision } \\
\text { rehabilitation, institutional homes for the } \\
\text { elderly or blind }\end{array}$} \\
\hline & & AMD & CHF4893 (impaired vision) & $£ 2213^{*} \dagger$ & \\
\hline & & & $\begin{array}{l}\text { CHF13098 (highly } \\
\text { impaired vision) }\end{array}$ & $£ 5924^{*} \dagger$ & \\
\hline
\end{tabular}

estimates were given precedence where available. Where costs were published before 2000, the costs have been inflated to December 2000 using the retail prices index. No discounting was applied.

The potential NHS, local and central government costs, and the probabilities of occurrence were multiplied and then the totals summed to give an estimate of the cost of blindness in first and subsequent years. Sensitivity analysis was carried out on these estimates to provide minimum and maximum estimates.

Estimates of the costs and probabilities and the sources from which they are derived are shown in Table 2.
No actual cost estimate for blindness registration was found. The cost shown is the doctor's sessional fee for completion of the BD8 form $^{14}$ plus the mean cost of a community occupational therapist for the initial assessment. ${ }^{15}$ These two elements represent the certification and registration elements of the process and are one-off costs in the first year of blindness. The estimate of proportion with blind registration is taken from a comparison of the prevalence of AMD causing partial and blind sight given in a recent review of prevalence ${ }^{16}$ and the number of registered blind and partially sighted people. Frequently, the RNIB survey has been quoted, suggesting that

Table 2 Basis of base case estimate of costs of blindness in AMD

\begin{tabular}{|c|c|c|}
\hline Outcome & Estimated cost (ref) & $\begin{array}{l}\text { Estimate of the proportion } \\
\text { with CNV and } 20 / 200 \text { visual } \\
\text { acuity who would have this } \\
\text { outcome in } 1 \text { year (ref) }\end{array}$ \\
\hline Blind registration* & $£ 59.70(14)+£ 37.71(15)$ & $94.5 \%(16)$ \\
\hline Low vision aids & $£ 136.33$ (19) & $33 \%(20,21)$ \\
\hline Low vision rehabilitation & $£ 205.30$ (15) & $11 \%(17)$ \\
\hline $\begin{array}{l}\text { Housing benefit and } \\
\text { council tax benefit }\end{array}$ & $£ 2714.40(22)$ & $45 \%(17)$ \\
\hline Social security & $£ 1924$ (23) & $63 \%(18)$ \\
\hline Tax allowance & $£ 319(24)$ & $5 \%(17)$ \\
\hline Depression & $£ 391.97(25)$ & $38.6 \%(26)$ \\
\hline Hip replacement & $£ 3669(27)$ & $5 \%(27-30)$ \\
\hline Community care & $£ 2848.63$ (15) & $6 \%(18)$ \\
\hline Residential care & $£ 15904.41$ (15) (-30\%†) & $30 \%(16,32,33)$ \\
\hline
\end{tabular}

*First year of blindness only, $\uparrow \sim 30 \%$ of residents pay for themselves.

only $50 \%$ of those eligible are actually registered. ${ }^{17}$ However, the prevalence estimate for vision impairment in this RNIB survey is well outside the 95\% confidence intervals of the more recent review (500 $000 \quad v \quad 312000)$, which suggests that the earlier study is less accurate. A second RNIB survey, focusing on older visually impaired people, gives a $93 \%$ registration rate. ${ }^{18}$

The low vision aid cost was an assessment of hospital eye service prescription forms in a district general hospital. ${ }^{19}$ Expert opinion has been used to estimate the proportion using low vision aids..$^{21}$ The cost of low vision rehabilitation is from a cost per care episode of a health authority community occupational therapist. ${ }^{15}$ The low vision rehabilitation proportion estimate comes from the RNIB survey. ${ }^{17}$ The housing benefit and council tax benefit are the annual averages for Great Britain for those aged over $60 .^{22}$ The social security cost is a year's worth of attendance allowance at the lower rate. ${ }^{23}$ The tax allowance assumes payment of basic tax rate $(22 \%){ }^{24}$ The cost of depression comes from a cost study of people with affective disorders who have been recently discharged from a long stay psychiatric hospital in the United Kingdom. ${ }^{25}$ The sample was small $(n=28)$ with average age of 62 years. It is recognised that this sample will not mirror closely the population 
suffering visual loss in AMD but this has been used in lieu of any better estimates. The proportion of older people with visual impairment who become depressed was estimated from a study validating a geriatric depression scale in people with visual impairment. ${ }^{26}$

The cost of hip replacement is from NHS reference costs. ${ }^{27}$ The proportion of blind people who fracture their hip and subsequently require a hip replacement operation is estimated from studies of visual difficulties of people in retirement homes. ${ }^{27-30}$ The community care element is the cost of a home care worker..$^{15}$ The residential care element is the cost of private residential care for elderly people, ${ }^{15}$ and proportion estimated from the census $^{31}$ and prevalence studies ${ }^{16}{ }^{32}$ taking into account that approximately 30\% of residents pay for themselves. ${ }^{33}$

The cost of the first year of blindness was found to be approximately $£ 6455$. In the second and subsequent years of blindness this figure fell to $£ 6295$ per year.

\section{SENSITIVITY ANALYSIS AROUND COST OF RAPIDLY DETERIORATING VISION}

There is uncertainty about particular components of the costs of blindness and probabilities of occurrence. These are summarised below and detailed in Table 3.

The high cost for blind registration is the examination for BD8 in own home plus an hour's face to face contact with a social worker. The low cost is just the fee for re-examination in consulting room for BD8 certification. ${ }^{14}$ The low cost of low vision aids is from an audit of an "in-house" NHS hospital low vision aid service. ${ }^{19}$ This was not taken as the standard cost as a recent survey has shown that only $32 \%$ of low vision aid services are of this type..34 For the percentages of low vision aid provision, the estimate by Margrain is the more recent $^{21}$ but the RNIB report may be more accurate. ${ }^{17}$ The high and low costs for low vision rehabilitation are the range for $50 \%$ of NHS trusts for occupational therapy services. ${ }^{27}$ The average housing benefit for disabled people aged under 60 is less than the average housing benefit for all aged under $60 . .^{22}$ Unfortunately, the data for the over 60 s are not subdivided in this way. However the average weekly rate varies around the United Kingdom from $£ 35.80$ in Scotland to $£ 58.80$ in Greater London. ${ }^{22}$ This geographical variation is also seen in council tax benefit. ${ }^{22}$ There is no information on the number of people who go blind in later life who receive this benefit. The estimate given will include people who were registered blind before and during their working life which may have caused a reduced earning capacity. The percentages also vary depending on whether the household is owned or rented. The higher cost estimate of attendance allowance (social security) is at the higher rate. ${ }^{23}$ The lower uptake from the first RNIB survey ${ }^{17}$ and higher uptake rate in the second RNIB survey ${ }^{18}$ suggests that the drive to increase uptake of attendance allowance has been successful to some extent. The lower cost estimate of tax allowance assumes payment of tax at the starting rate of $10 \%$. In the first RNIB survey, ${ }^{17}$ overall only $5 \%$ claimed that they received this allowance, but $18 \%$ not in work stated that they claimed it. It is unclear from the report whether this group was of working age or of all ages. No figure was given for people over retirement age or registered blind.

There is very little evidence about the cost of depression in the elderly. ${ }^{35}$ The costs quoted are the only UK costs found that were not associated with or comparing the costs of different drug treatments or conditions..$^{25}$ Estimates of depression rates vary widely. This may be to do with the method of measurement of depression used in the three studies quoted-GHQ, ${ }^{36}$ Geriatric Depression Scale, ${ }^{26}$ and the Wakefield

Table 3 Basis of sensitivity analysis on costs of blindness in AMD (references are in parentheses)

\begin{tabular}{|c|c|c|c|c|}
\hline Outcome & High cost & Low cost & $\begin{array}{l}\text { High percentage } \\
\text { probability }\end{array}$ & $\begin{array}{l}\text { Low percentage } \\
\text { probability }\end{array}$ \\
\hline Blind registration & $£ 169.73(14,15)$ & $£ 40.10(14)$ & $94.5 \%(16)$ & $50 \%(17)$ \\
\hline Low vision aids & $£ 136.33$ (19) & $£ 56.41$ (19) & $74 \%(17)$ & $33 \%(21)$ \\
\hline $\begin{array}{l}\text { Low vision } \\
\text { rehabilitation }\end{array}$ & $£ 309(27)$ & $£ 125$ (27) & $11 \%(17)$ & $11 \%(17)$ \\
\hline $\begin{array}{l}\text { Housing benefit and } \\
\text { council tax benefit }\end{array}$ & $£ 3588(22)$ & $£ 2412.80(22)$ & $73 \%(17)$ & $21 \%(17)$ \\
\hline Social security & $£ 2875.60(23)$ & $£ 0$ & $63 \%(18)$ & $17 \%(17)$ \\
\hline Tax allowance & $£ 319(24)$ & $£ 145(24)$ & $18 \%(17)$ & $5 \%(17)$ \\
\hline Depression & $£ 391.97$ (25) & $£ 391.97$ (25) & $50 \%(36)$ & $6 \%(37)$ \\
\hline Hip replacement & $£ 3933$ (27) & $£ 1177$ (27) & $24.7 \%(28,30,38)$ & $0.5 \%(27,31)$ \\
\hline Community care & $£ 4758.80$ (15) & $£ 1138.36$ (15) & $40 \%$ (17) & $6 \%(18)$ \\
\hline Residential care & $£ 23584.28$ (15) & $£ 7843.27$ (15) & $56 \%(39)$ & $13 \%(29)$ \\
\hline
\end{tabular}

Self-rating Depression Scale. ${ }^{37}$ The high and low costs of hip replacement are the range for $50 \%$ of NHS trusts for the operation. ${ }^{27}$ The probability of hip replacement varies widely because there are no longitudinal studies of blind people looking for this outcome. The proportions can be estimated from the percentage falls in older people with visual impairment, ${ }^{28}$ the rate of hip replacement following a fall ${ }^{30}$ and the prevalence of blindness, ${ }^{38}$ or by the total number of hip replacements ${ }^{27}$ and the population over 65 years. ${ }^{31}$

The higher cost of community care is for a home care worker for 1 hour per day whereas lower cost is for 2 hours per week. ${ }^{15}$ The lower estimate of percentage home help has been used in the main estimate as it is from a later source, ${ }^{18}$ and because there is a trend for home help to be increasingly provided by private agencies, paid for by the individual from their attendance allowance. The higher cost of residential care is the annual cost for local authority residential care for elderly people. The lower cost is for local authority sheltered housing. ${ }^{15}$ There are studies of the proportion of registered blind people already in residential care but not the proportion of blind people who have to enter residential care because of their low vision. The estimates of registered blind as a result of AMD in the three case studies used are $5 \%,{ }^{29} 11.8 \%,{ }^{32}$ and $22 \% .{ }^{39}$ From these, using census data for the numbers of elderly in nursing and residential homes and the prevalence of AMD in the elderly, ${ }^{16}$ the approximate proportion of people with low vision caused by AMD who enter residential care can be calculated. This was reduced by $30 \%$, as approximately $30 \%$ of residents are self payers. ${ }^{33}$

The cost range for the first year of blindness was approximately £1375$£ 17$ 100. In the second and subsequent years of blindness this range fell to $£ 1325-£ 16800$ per year. The highest cost by far was the cost of residential care and the cost of blindness was most sensitive to the percentage of people with AMD who require this.

\section{CONCLUSIONS}

It is acknowledged that any top down study such as this can only give an approximate cost of blindness. This can be readily seen from the wide cost range provided by the sensitivity analysis which encompasses most of the other estimates. The estimates below $£ 1000$ in Table 1 were felt to be implausibly low, considering the basic level of help offered to all registered blind people in the United Kingdom. However, much of the uncertainty in the sensitivity analysis is associated with the cost of 
residential care. The excess admission to care homes caused by poor vision is impossible to quantify accurately at the moment. Without a longitudinal study of people with AMD or other conditions causing low vision who subsequently enter residential care, this will continue to cause wide variation in the cost of blindness estimates.

It is noticeable that most of the low estimates are associated with cost utility analyses of verteporfin for Novartis Pharmaceuticals AG, Switzerland, before the NICE technology appraisal of photodynamic therapy. These low estimates are surprising. The more that is spent on support for a blind person, the more impact treatment would have. Logically one would expect that if the cost of treatment is fixed, the more the cost of blindness, and the lower the cost utility of that treatment. This was borne out by the sensitivity analysis undertaken in the technology appraisal report. ${ }^{1}$ Varying the cost of blindness made the cost utility estimate range from a relatively efficient use of healthcare resources to completely inefficient.

Ideally a bottom up costing study should be undertaken on its own, independently of cost utility, other analyses, or any vested interests. This would follow a cohort of older people with failing eyesight and record the costs incurred. It is inevitable that increasing numbers of cost utility studies will be performed in the future, not least because of the new treatments being developed for AMD such as transpupillary thermotherapy and anecortave acetate. In order to carry out accurate cost utility analyses of these treatments an accurate cost of blindness needs to be established.

Br J Ophthalmol 2003;87:1201-1204

\section{Authors' affiliations}

C Meads, C Hyde, West Midlands Health Technology Assessment Group, Department of Public Health and Epidemiology, University of Birmingham, Edgbaston, Birmingham B15 $2 \pi$, UK

Correspondence to: Dr Catherine Meads, West Midlands Health Technology Assessment
Group, Department of Public Health and Epidemiology, University of Birmingham Edgbaston, Birmingham B15 2TT, UK; c.a.meads@bham.ac.uk

\section{REFERENCES}

1 Meads C, Salas C, Roberts T, et al. Clinical effectiveness and cost utility of photodynamic therapy for wet age-related macular degeneration. London: NICE, 2002.

2 Royal National Institute for the Blind. The costs of blindness. Campaign Report No 12. London: RNIB, 2000.

3 Javitt JC, Aiello LP. Cost effectiveness of detecting and treating diabetic retinopathy. Ann Intern Med 1996; 124:164-9

4 Javitt JC, Aiello LP, Chiang Y, et al. Preventive eye care in people with diabetes is cost-saving to the federal government. Diabetes Care 1994;17:909-17.

5 Chiang Y, Bassi $\sqcup$, Javitt JC. Federal budgetary costs of blindness. Milbank Quarterly 1992:70:319-40.

6 Sharma S, Brown GC, Brown MM, et al. The cost effectiveness of photodynamic therapy for fellow eyes with subfovial choroidal neovascularisation secondary to age-related macular degeneration. Ophthalmology 2001; 108:2051-9.

7 Evans J. Causes of blindness and partial sight in England and Wales, 1990-1991. Report No 57 London: HMSO, 1995.

8 Wright SE, Keeffe JE, Thies LS. Direct costs of blindness in Australia. Clin Exp Ophthalmol 2000;28:140-2

9 ScHARR. Section 1.4. Economic burden of AMD and Appendix 2, Care pathways. Sheffield: Novartis Ophthalmics AG Submission to NICE, 2001.

10 Greiner RA. Cost of care for patients with agerelated macular degeneration in Switzerland and cost-effectiveness of treatment with verteporfin therapy. Sem Ophthalmol 2001;16:218-22.

11 Smith D, Drummond MF, Fenn P. Costs and effects of PDT with verteporfin therapy in the UK. (Unpublished)

12 Foulds WS, McCuish A, Barrie T, et al. Diabetic retinopathy in the West of Scotland: its detection and prevalence and the cost effectiveness of a proposed screening programme. Health Bull 1983:41:318-26.

13 Dasbach EJ, Fryback DG, Newcomb PA, et al. Cost-effectiveness of strategies for detecting diabetic retinopathy. Med Care 1991;29:20-39.

14 NHS Executive. Fees and allowances payable to doctors for sessional work in the community health services, medical services to local authorities (under collaborative arrangements), medical examinations of prospective National Health Service employees and notification of infectious diseases and food poisoning. Leeds: NHS Executive, 2000.

15 Netten A, Curtis L. Unit costs of health and social care, 2000. Canterbury: PSSRU, University of Kent, 2000.

16 Fletcher A, Donoghue M, Owen C. Low vision services for people with age related macular degeneration in the UK: a review of service need and provision. London: London School of Hygiene and Tropical Medicine.(Submitted to the Macular Disease Society, June 2001).
17 Bruce I, McKennell A, Walker E. Blind and partially sighted adults in Britain: the RNIB survey. London: Royal National Institute for the Blind, 1991.

18 Baker M, Winyard S. Lost vision. Older visually impaired people in the UK. London: RNIB, 1998.

19 Landers A, Tapley J, Billington B, et al. Cheaper can be better: cutting costs and improving low vision aid service. Br J Vis Imp 1999;17:1 11-15.

20 Margrain TH. Minimising the impact of low vision aids. BMJ 1999;318:1504.

21 Margrain TH. Helping blind and partially sighted people to read: the effectiveness of low vision aids. Br J Ophthalmol 2000;84:919-21.

22 Department for Work and Pensions. Housing benefit and council tax benefit. Annual summary statistics. May 2000. London: ONS, 2001.

23 Department of Social Security. Attendance allowance (AA). www.dss.gov.uk/lifeevent/ benefits/attendance_allowance.htm (access date 1 October 2001).

24 Inland Revenue. Rates and allowances-income tax. www.inlandrevenue.gov.uk/rates/it.htm (access date 1 October 2001).

25 Knapp M, Beecham J, Fenyo A, et al. Community mental health care for former hospital inpatients, predicting costs from needs and diagnoses. Br J Psychiatry 1995;166(Suppl 27):10-18.

26 Galaria II, Casten RJ, Rovner BW. Development of a shorter version of the geriatric depression scale for visually impaired older patients. Int Psychogeriatr 2000;12:435-43.

27 Department of Health. Reference costs 2000. London: DoH, 2000.

28 Jack Cl, Smith T, Neoh C, et al. Prevalence of low vision in elderly patients admitted to an acute geriatric unit in Liverpool: elderly people who fall are more likely to have low vision. Gerontology 1995;41:280-5

29 Sturgess I, Rudd AG, Shilling J. Unrecognised visual problems amongst residents of Part III homes. Age Ageing 1994;23:54-6.

30 Anon. Predicting falls in older people in the community. Bandolier 2001;8.

31 Office for National Statistics. The 1991 census. London: Stationery Office, 2001.

32 Tielsch JM, Javitt JC, Coleman A, et al. The prevalence of blindness and visual impairment among nursing home residents in Baltimore. N Engl J Med 1995:332:1205-9.

33 The Royal Commission on Long Term Care. With respect to old age: long-term care-rights and responsibilities. London: Stationery Office, 1999.

34 Ryan B, Culham L. Fragmented vision. Survey of low vision services in the UK. London: RNIB/ Moorfields Eye Hospital NHS Trust, 1999.

35 Hughes D, Morris S, McGuire A. The cost of depression in the elderly. Effects of drug therapy. Drugs Aging 1997:10:59-68.

36 Scott IU, Schein OD, Fever WJ, et al. Emotional distress in patients with retinal disease. Am J Ophthalmol 2001;131:584-9.

37 Evans RL. Loneliness, depression and social activity after determination of legal blindness. Psychol Rep 1983;52:603-8.

38 Government Statistical Service. Registered blind and partially sighted people Year ending 31 March 1997. England. Report No A/F 97/7. London: Department of Health, 1997.

39 Van Newkirk MR, Weih L, McCarty CA, et al. Visual impairment and eye diseases in elderly institutionalised Australians. Ophthalmology 2000;107:2203-8. 